\title{
Analysis of the experience of renovating industrial enterprises into hotels in China
}

\author{
Zehong Gong* and Larysa Bridnia \\ Architecture, Architecture Department, Kyiv National University of Construction and Architecture, Ukraine
}

\begin{abstract}
The adaptive reuse of abandoned industrial buildings is a very hot topic in the post-industrial modern society. The re-equipment of these buildings and territories can be carried out in different directions for different functions: exhibition complexes, public centers, museums, trade enterprises. This study focuses on the renovation of such industrial buildings into hotels in China. The experience of reconstruction and related literature has been studied. The study found that since most of the post-industrial buildings in China are small in size, they are suitable for repurposing as boutique hotels. Large industrial buildings and complexes in mega cities in China can be converted into luxury hotels. Renovation of old industrial buildings into hotels makes it possible to double the average lifespan of buildings - approximately up to 60-65 years.
\end{abstract}

\section{Introduction}

In today's high-tech society, information technology industries are constantly supplanting more traditional industrial manufacturing industries in China. Accordingly, a large number of industrial buildings remain abandoned and destroyed. At the same time, most of these buildings are of great interest in terms of preserving the historical and cultural heritage of the region, as well as important for preserving the urban planning integrity of the city. The renovation of such enterprises takes place in different directions. The experience of converting industrial enterprises into hotels remains poorly studied.

Adaptive building reuse is a special form of renovation that brings many special challenges and challenges for designers [1]. Very often, modern technologies are difficult to fit into the existing historical structure of the old building. Difficulties arise in two directions compliance with modern rules and regulations and modern design requirements [2]. Some elements of buildings are reworked several times to find a worthy embodiment for them in a new building, which significantly affects the final cost. Designing reusable buildings takes more time and effort from the design team [2]. Designers must understand the importance of preserving historically, culturally and architecturally valuable parts and elements of buildings, as well as anticipate the consequences of using reclaimed elements. Aware of the significant increase in construction costs involving the re-use of old elements, they should strive to use new design and construction methods to reduce potential adaptation costs. Otherwise, this approach may not be widespread and successful.

Pollution of abandoned industrial enterprises is one of the main problems of re-adaptive use of such territories [3] The cost of cleaning them significantly affects the total cost of the renovation. The experience of adapting industrial buildings for high-class housing has shown that often excessive cleaning, renovation and hiding old walls behind new ones leads to emasculation and loss of cultural value for society. [4].

Until 2006, little attention was paid to the protection of industrial heritage in China. As of 2006, 2,352 buildings were under protection (information from the Ministry of Culture of China), and only 140 of them were associated with industrial heritage. April 18, 2006 'Wuxi Suggestions' were put forward at the Forum of China's Industrial Heritage Protection [5]. The concept of "industrial heritage" in China was defined and seven programmatic steps were identified for the protection and reuse of industrial heritage. This opened a new path for China in terms of preserving, protecting and using industrial cultural heritage.

Que studied the experience of protecting industrial heritage around the world and put forward proposals for its application in the Chinese context. He paid particular attention to the need to preserve Chinese agricultural industrial enterprises, as well as national industrial enterprises of the industrial construction period. [6]. Yu and Fang proposed to identify, study and document all of China's industrial heritage in terms of the prospects for its further use. The history of the formation of China's industrial heritage was studied, four periods before and three periods after the founding of the People's Republic of China were identified. In accordance with these periods, types, costs were identified and the potential for reuse of such establishments was considered. They emphasized the public interest and value of the protection and adaptive reuse of industrial heritage [7].

These systemic studies have created the basis for further exploration and reuse of China's industrial heritage.

This study defines the main boundaries of protection

\footnotetext{
* Corresponding author: zehong.g a@knuba.edu.ua.
} 
and preservation of cultural industrial heritage in combination with its reconstruction and adaptation to a new function. The stages of systematization and evaluation of such enterprises are highlighted, the need to change the attitude of society towards industrial heritage is revealed, as well as all the advantages of their reuse for a hotel function. The modern tendencies of re-profiling industrial enterprises for hotels have been studied, ways of preserving industrial relics, taking into account the economic effect of their reuse as hotels, primarily as boutique hotels, have been determined.

\section{Methods}

This study is based on the methods of statistical analysis, which includes a documentary study of cases of reconstruction of industrial buildings for hotels, their field examination and photographic recording. Researched project documentation and accompanying earlyjournalistic literature, as well as Internet sources. A survey of stakeholders (designers, developers, hoteliers and consumers) was conducted, and the websites of hotels rebuilt from industrial enterprises were studied. The research was carried out on 52 industrial buildings converted from 1990 to 2020 into hotels in China.

\section{Results}

\subsection{General information on the reuse of industrial buildings as hotels in China.}

The study included 52 cases of adaptive reuse of industrial buildings for hotels in China (identified as of 2019). The total area of such renovation exceeded 360,000 square meters. Such buildings are found in the first-, second-, third-tier cities and in the countryside. The capacity of such hotels ranges from 1 to 398 rooms. The comfort level of hotels varies from 2-5 stars, and the cost of living is from $118 \mathrm{CYN}$ (for 2-star hotels) to $5000 \mathrm{CYN}$ (for 5-star hotels).

The first case of reuse of an industrial building for a hotel in China was in 1995, at that time the life cycle of the building was 55.5 years. As of the beginning of 2020, the average lifespan of such buildings was 65.2 years. The longest lifespan was 214 years, and the shortest was 30 years.

The largest number of such examples is in Shanghai (18 cases), in Beijing and Hangzhou - 5 cases each, in Xi'an - 4 projects.

Table1. The statistics information on 52 repurposed industrial hotels.

\begin{tabular}{|c|c|c|c|c|c|}
\hline NO & Name of project & lifespan & Location & price & $\begin{array}{l}\text { Number of } \\
\text { rooms }\end{array}$ \\
\hline 1 & $\begin{array}{c}\text { Jinjiang Inn (Shanghai Zhongshan } \\
\text { Park) }\end{array}$ & 37 & Shanghai & 288 & 190 \\
\hline 2 & Manshan hotel & 62 & Shanghai & 358 & 2 \\
\hline 3 & One Hundred Holiday Hotel & 91 & Shanghai & 188 & 40 \\
\hline 4 & Jinchang hotel & 32 & Shanghai & 203 & 266 \\
\hline 5 & Hanting hotel & 73 & Shanghai & 218 & 8 \\
\hline 6 & 24K International Hotel & $\mathrm{Na}$ & Shanghai & 170 & 29 \\
\hline 7 & $\begin{array}{c}\text { Jinjiang Inn (Shanghai Huamu } \\
\text { road) }\end{array}$ & $\mathrm{Na}$ & Shanghai & 368 & 189 \\
\hline 8 & Yu Chuan Chateau hotel & 41 & lan tian & 332 & 249 \\
\hline 9 & motel168 Hotel & 27 & Shanghai & 137 & \\
\hline 10 & Yayue hotel (Aiben) & 50 & Shanghai & 98 & \\
\hline 11 & $\begin{array}{l}\text { China Community Art and Culture } \\
\text { Hotel }\end{array}$ & 50 & Qindao & 479 & 255 \\
\hline 12 & CityInn hotel & 40 & Chengdu & 155 & 152 \\
\hline 13 & motel 268 Hotel & 88 & Shanghai & 368 & 77 \\
\hline 14 & Nanqun hotel & $\mathrm{Na}$ & Shanghai & 542 & 162 \\
\hline 15 & Jinjiang Inn & $\mathrm{Na}$ & Shanghai & 188 & 39 \\
\hline 16 & $3+1$ bedroom & 225 & Beijing & 218 & 518 \\
\hline 17 & Gracie Art Hotel 798 & 63 & Beijing & 580 & 24 \\
\hline 18 & $\begin{array}{l}7 \text { Days InnGuangzhou Panyu City } \\
\text { Bridge }\end{array}$ & $\mathrm{Na}$ & Guangzhou & 198 & 97 \\
\hline 19 & Fortune Ancient Canal Hotel & 73 & Wuxi & 389 & 49 \\
\hline 20 & Mingdi Boutique Hotel & 170 & Shanghai & 485 & 2 \\
\hline 21 & Mutianyu tile factory Hotel & 59 & Beijing & 359 & 216 \\
\hline 22 & WaterHouse & 90 & Shanghai & 268 & 117 \\
\hline 23 & Pier One Hotel & 87 & Shanghai & 418 & 25 \\
\hline 24 & Scholars Hotel Suzhou Pingjiangfu & 35 & Suzhou & 688 & 31 \\
\hline 25 & Hansheng hotel & 85 & Shanghai & 789 & 110 \\
\hline 26 & Phoenix Mountain Hotel & 50 & Hangzhou & 272 & 130 \\
\hline 27 & $\begin{array}{l}\text { Zuoyouke Theme Hotel (Xi'an } \\
\text { Gaoxin) }\end{array}$ & 40 & Xianan & 215 & 65 \\
\hline 28 & Sheng Gao Hotel & 47 & Hangzhou & 590 & 30 \\
\hline 29 & Chunqiu hotel & 59 & Xianan & 449 & 193 \\
\hline 30 & UHome & 99 & Tianjin & 420 & 24 \\
\hline 31 & Dahua 1935 Theme Hotel & 85 & Xianan & 199 & 19 \\
\hline 32 & Qingdao Tiger Hostel & 110 & Qindao & 269 & 88 \\
\hline 33 & Hui hotel & 40 & Shenzhen & 1050 & 96 \\
\hline 34 & Youth Hotel of iD Town & 31 & Shenzhen & 399 & 1 \\
\hline
\end{tabular}




\begin{tabular}{|c|c|c|c|c|c|}
\hline 35 & Ovolo Southside hotel & 44 & Hongkong & 888 & 84 \\
\hline 36 & 1 Hugu Hotel & 62 & Hangzhou & 713 & 88 \\
\hline 37 & Jiuhou Theme Hotel & 89 & Ningbo & 293 & 16 \\
\hline 38 & Cheery Canal Hotel & 69 & Hangzhou & 548 & 3 \\
\hline 39 & Huanyuan hotel & 28 & Shanghai & 239 & 17 \\
\hline 40 & OneHouse & 70 & Shanghai & 629 & 66 \\
\hline 41 & joyardhotel & 38 & Guangzhou & 569 & 55 \\
\hline 42 & $\begin{array}{l}\text { Zuoyouke Theme Hotel (Steel } \\
\text { factory) }\end{array}$ & 62 & Xianan & 589 & 4 \\
\hline 43 & Ouwei Design Hotel & 35 & Hangzhou & 980 & 54 \\
\hline 44 & $\begin{array}{c}\text { Taoxichuan International Trade } \\
\text { Hotel }\end{array}$ & 62 & Jingdezhen & 228 & 26 \\
\hline 45 & Beijing Backyard Inn & 40 & Beijing & 523 & 13 \\
\hline 46 & $\begin{array}{l}\text { Cangge Holiday Inn Beijing } \\
\text { Shougang }\end{array}$ & 60 & Beijing & 316 & 88 \\
\hline 47 & The Journey Hotel & 30 & Dongguan & 399 & 108 \\
\hline 48 & Wuguan hotel & 64 & Wenzhou & 1238 & 35 \\
\hline 49 & Alila Hotel & 60 & yangshuo & 2565 & 159 \\
\hline 50 & Narada ResortSpa Nanxun Giant & 69 & Huzhou & 668 & 131 \\
\hline 51 & Sure 24 rooms hotel & 62 & Chengdu & 279 & 140 \\
\hline 52 & Holiday inn riverside & 83 & Wuhan & 90 & 32 \\
\hline
\end{tabular}

\subsection{Location}

Industrial buildings converted to hotels in one-tier cities accounted for $53.8 \%$, which exceeds the total number of such examples in other cities. The number of repurposed projects in the cities of the first and second tier reached $86.5 \%$, as shown in Figure 1.

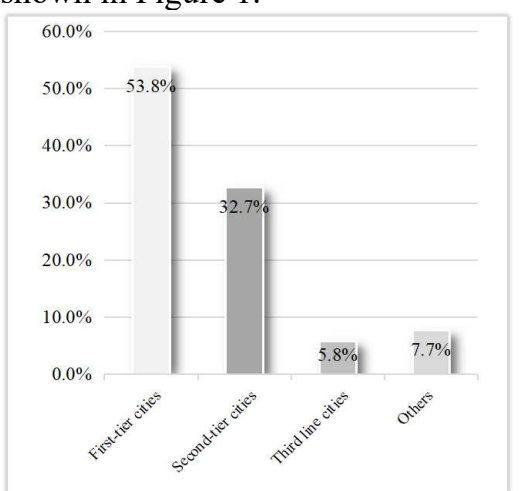

Fig1. The city where the industrial buildings is repurposed as hotels in China.

From this information, we can conclude that such renovation may be the most attractive for cities of the firstand second-tier cities.

Studies of the influence of climatic features have shown that the largest percentage of such reconstructions occur in areas with warm climates.

When it comes to refurbishing industrial buildings in a hotel, which includes the installation of additional doors, vestibules and heating systems - to prevent the ingress of cold air, it is economically much more profitable than the demolition of existing buildings and new construction. Nevertheless, the percentage of renovations of industrial buildings in the hotel in Southern China (40 facilities) is higher than in the North of China (12 facilities). It seems that the level of urbanization affects this factor more than environmental protection and energy conservation. At the same time, this indicates a high potential for the development of this area in the cold regions of northern China.

At the same time, an important indicator is the location of the object relative to the historic city center. The largest share of reusable objects falls on the areas close to the historic center. This attraction is due to both the prestige of the district and the higher percentage of historic industrial buildings that need to be preserved. More detailed information on this issue is given in Figure 2.

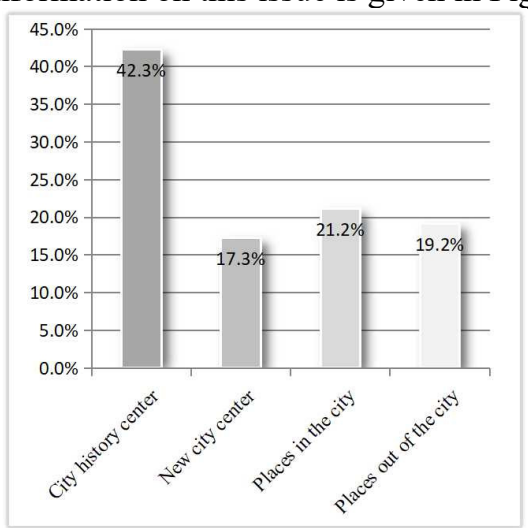

Fig2. Location of industrial buildings repurposed as hotels in the city.

Among the 52 examples of renovation of industrial buildings for hotels, the largest percentage falls on detached buildings $(61.5 \%$ or 32 cases $)$. At the same time, during the reconstruction of industrial parks, approximately $9.6 \%$ are hotel projects as part of other public buildings and $28.8 \%$ - individual hotel buildings. A very small percentage, only about $10 \%$ (including 6 cases), are examples where an industrial building was converted into a hotel, and then still such a hotel closed and the building was demolished or converted again. Among these 6 cases - 2 examples - were erected under the project of reconstruction of a separate building, and 4 - as a part of renovation of industrial parks.

\subsection{Lifespan}

Industrial buildings of different construction periods in China differ greatly in terms of the use of building structures and materials. Therefore, it was important to explore the potential for conversion of industrial buildings of different construction periods into hotels. 


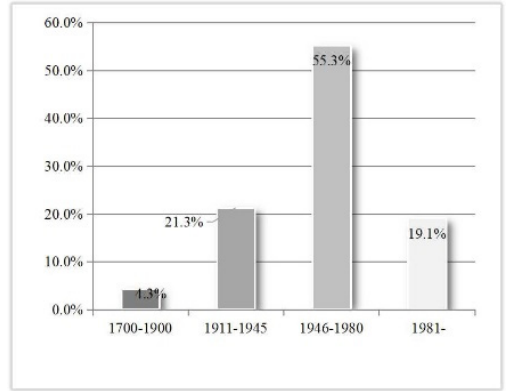

Fig3. The original completion time of industrial buildings.

Most examples of renovation of industrial buildings in the hotel belong to buildings built in 1945-1985. This is due to the fact that China has the largest number of industrial buildings during this period of construction, as well as such buildings are well preserved and suitable for further reconstruction.

Significantly fewer reconstructions of industrial buildings for hotels occurred in the building of 1700-1900. Although such industrial buildings are artistic and architectural expressive, contain many features of national culture and may seem attractive for reconstruction in a boutique hotel, but at the same time they are under enhanced protection of China's cultural heritage. In addition, the reconstruction of the hotel function requires significant changes in the original structure of buildings, and therefore it is very difficult in such a reconstruction to preserve the original characteristic structure, which is under protection.

Such buildings are often converted into museums, exhibition complexes or community centers.

Most industrial buildings built after 1985 continue to operate as industrial enterprises and do not require reconstruction.

Reconstruction of industrial buildings for hotels in China has a pronounced upward trend. The first such project was Jinjiang Inn (on Zhongshan road) completed in 1995, which is still used as a hotel. In total, from 1990 to 2008,15 projects were implemented. From 2008 to 2014, 20 projects were completed, and from 2015 to 2019 - 17 projects.

The design period for the construction of new buildings is 50 years, at the same time, the average life cycle of buildings in China is 25-30 years. Studies have shown that the average lifespan of industrial buildings converted into hotels is 65.5 years, and therefore twice the average and much higher than the design cycle of new construction.

\subsection{The dimensions of repurposed hotels}

Among the 50 projects where the exact area could be measured, $57 \%$ had an area of less than 5,000 m2, 24\% had an area of 50,000 to $10,000 \mathrm{~m} 2$, and $22 \%$ had an area of more than $10,000 \mathrm{~m} 2$.

As Figure 4 shows, among the 52 projects for the reconstruction of industrial buildings for hotels, more than $60 \%$ are $4-6$-storey hotels.

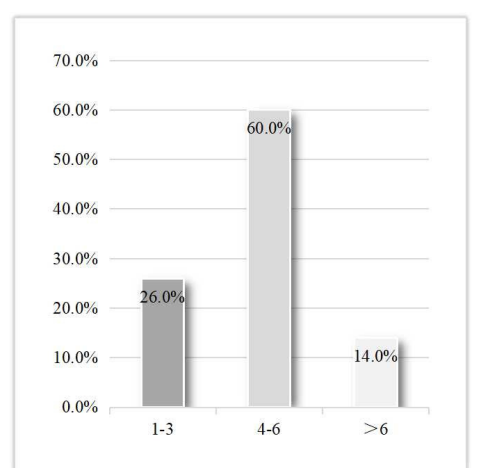

Fig4. The superficiality of repurposed industrial hotels.

Hotels that are reconstructed on the basis of industrial buildings mostly have a relatively small capacity. See Figure 5. More than $60 \%$ of such hotels have less than 100 rooms. This is due to both the structure of the industrial buildings and the fact that boutique hotels, which are usually converted to such buildings are generally small capacity, which allows such institutions to have an individual atmosphere of industrial culture.

\subsection{Comfort level of the hotels}

The star rating of 52 reconstructed hotels is shown in Table 2. 52 examples of post-industrial hotels were developed, of which: 28 - in first-tier cities, 24 in the cities of other tiers. In first-tier cities, $75 \%$ are 2-3-star hotels, 4-star hotels are $21 \%$, and five-star hotels are only $3.4 \%$, in non-first-tier the situation looks the opposite: $58.3 \%$ account for 4-5 star hotels and 41.7\% - for 2-3 star hotels. And in such cities a large percentage of 5-star hotels - 25\%.

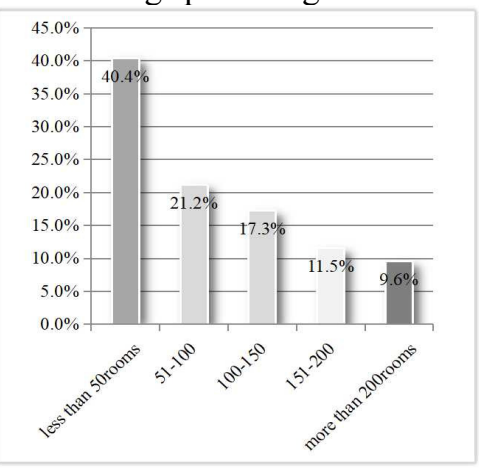

Fig5. The room number of repurposed industrial hotels.

Table2. The statistics information on 52 repurposed industrial hotels.

\begin{tabular}{|c|c|c|c|c|c|}
\hline & 2 -star & 3 -star & 4-star & 5 -star & $\begin{array}{c}\text { Number of } \\
\text { cases }\end{array}$ \\
\hline 52 cases & $28.8 \%$ & $30.8 \%$ & $26.9 \%$ & $13.5 \%$ & 52 \\
\hline $\begin{array}{c}\text { In first-tier } \\
\text { cities }\end{array}$ & $39.3 \%$ & $35.7 \%$ & $21.4 \%$ & $3.6 \%$ & 28 \\
\hline $\begin{array}{c}\text { Not in first- } \\
\text { tier cities }\end{array}$ & $16.7 \%$ & $25.0 \%$ & $33.3 \%$ & $25.0 \%$ & 24 \\
\hline
\end{tabular}

The analysis of pricing in such hotels is also carried out. Among the 52 projects, the price of a standard room per night in a 2-3-star hotel in a city with a population of more than 10 million is similar to that of a city with a population of less than 10 million. At the same time, the cost of living in standard rooms in a 4-5-star hotel is 1.52 times higher than the price of the corresponding hotels in cities with a population of more than 10 million (see 
Figure 6).

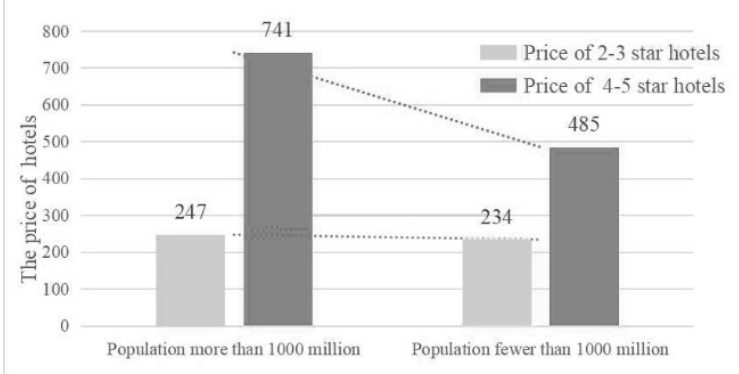

Fig6. The correlation between population and star ranking of hotels.

\section{Conclusion}

The successful repurposing of industrial buildings as hotels can extend the life of the building and avoid damage to the building caused by the second reconstruction. The following aspects are worth considering via statistical study. It is more suitable to be repurposed as a boutique hotel with low floor area ratio. In such a hotel, it creates the best conditions for retaining the industrial culture. To excavate the cultural value of the legacy buildings and use them to enhance the added value of hotel products, so as to achieve the unity of cultural appeals and business models for enterprises to win higher profits.

Based on statistical analysis, it has been found that in cities with a permanent population of more than 10 million, most industrial buildings are converted into 2-3-star hotels, while in other cities buildings are more often converted into 4-5-star hotels. This model seems to be the most economically determined. This is due to the higher flow of middle-class customers and the low consumer capacity of China as a developing country. The price per room per night of 4-5 star hotels in first and second level cities with a population of over 10 million is almost twice as high as in smaller cities, as shown in Figure 6. In such first-tier cities, the occupancy rate of 4-5-star hotels in first-tier cities is quite low, with a record low level of $8.3 \%$ in April 2020 [8].

The nightly price of 52 repurposed hotels is higher than non-repurposed hotels for the same star ranking and the same region. At the same time, their lifespans are 40.535.5 years longer than the average life span of all buildings in China, which is twice the average life span of all buildings in China. City managers guide investors to participate in the repurposing of industrial buildings as hotels in suitable locations, which can achieve the continuation of the industrial building heritage and economic benefits.

In terms of various urban, socioeconomic, structural, and styles aspects, a statistical study and detailed data is of vital importance for the analysis and decision-making of stakeholders in the repurposing and reusing of industrial buildings. At the same time, the collection of data and the establishment of databases pose challenges for future city managers.

\section{References}

1. Fisher-Gewirtzman, D. Adaptive reuse architecture documentation and analysis. Journal of Architectural Engineering Technology, 5(3) (2016). https://doi.org/10.4172/2168-9717.1000172

2. Conejos, S., Langston, C., Chan, E. H. W., \& Chew, M. Y. L. Governance of heritage buildings: Australian regulatory barriers to adaptive reuse. Building Research and Information, 44(5-6), 507-519.(2016). https://doi.org/10.1080/09613218.2016.1156951

3. Bachman. L. R. New professionalism: The postindustrial context. Building Research and Information, $41(6)$

752-760.(2013). https://doi.org/10.1080/09613218.2013.804778

4. Clark, J. Adaptive reuse of industrial heritage: Opportunities \& challenges. Heritage Council of Victoria, 1-7.(2013).

5. $\mathrm{Xu}, \mathrm{Y}$. Reflections on industrial heritage protection in China. e-Phaïstos, I(1), 111-119. (2012).https://doi.org/10.4000/ephaistos.300

6. Que, W-M. On International Protection and Research of Industrial Property. Journal of Peking University (Natural Science), 04, 523-534.(2007). (In Chinese)

7. Yu K.-J., \& Fang W.-L., Preliminary Exploration of Chinese Industrial Heritage. Chinese Journal of Architecture. 08,12-15. (2006). (In Chinese)

8. Beijing Municipal Commission of Tourism Development. China Beijing: Star-Rated Hotel: Room Occupancy Rate, 5 Star Economic Indicators. (2020).https://www.ceicdata.com/en/china/starratedhotel-beijing/beijing-starrated-hotel-roomoccupancy-rate-5-star 